Pacific Journal of Mathematics

THE SPECTRAL RADIUS OF AVERAGING OPERATORS 


\section{THE SPECTRAL RADIUS OF AVERAGING OPERATORS}

\section{DAVID W. BOYD}

This paper is concerned with the properties of certain operators which act on rearrangement invariant spaces of functions. The spectral radius of such an operator is determined precisely in terms of the spectral radius of the translation operator $E_{s}$. A new inequality is obtained for the norm of the iterates of the averaging operator $P$ in terms of the norm of $E_{s}$.

We consider further properties of the operators $P_{a}$ and $Q_{a}$ which were exploited in [2] (with a slightly different notation).

If $f$ is a measurable function defined on $R^{+}=[0, \infty)$, then $P_{a} f$ and $Q_{a} f$ are given by the following:

$$
\begin{aligned}
& P_{a} f(t)=\int_{0}^{1} s^{-a} f(s t) d s=t^{a-1} \int_{0}^{t} s^{-a} f(s) d s \\
& Q_{a} f(t)=\int_{1}^{\infty} s^{a-1} f(s t) d s=t^{-a} \int_{t}^{\infty} s^{a-1} f(s) d s,
\end{aligned}
$$

whenever the defining integrals exist a.e.

We define the translation operator $E_{s}$ by

$$
E_{s} f(t)=f(s t), \quad 0<s<\infty, \quad t \in R^{+} .
$$

Thus, in some sense which need not be made precise here,

$$
P_{a}=\int_{0}^{1} s^{-a} E_{s} d s, \text { and } Q_{a}=\int_{1}^{\infty} s^{a-1} E_{s} d s .
$$

Now, suppose that $X$ is a rearrangement invariant Banach space as defined in [1]. It was shown in [2] that it is important to know whether or not the operators $P_{a}$ and $Q_{a}$ define continuous mappings of $X$ into itself. In terms of the norm of $E_{s}$, which we write as $h(s)=\left\|E_{s}\right\|$, a sufficient condition in order that $\left\|P_{a}\right\|<\infty$ is that

$$
\int_{0}^{1} s^{-a} h(s) d s<\infty,
$$

and a bound for the norm is given by

$$
\left\|P_{a}\right\| \leqq \int_{0}^{1} s^{-a} h(s) d s .
$$

A similar expression holds for $\left\|Q_{a}\right\|$. This is a consequence of Theorem 3.1 of [1]. Here, we will always adopt the convention that if $P_{a}$ is not a bounded operator from all of $X$ into itself then $\left\|P_{a}\right\|=\infty$. 
For the special case $a=0$, it was shown in [1], that (5) is a necessary condition for $\left\|P_{0}\right\|<\infty$, and in fact

$$
\left\|P_{0}\right\| \leqq \int_{0}^{1} h(s) d s \leqq 2 \sqrt{2}\left\|P_{0}\right\|
$$

Our first object here is to show that (5) is a necessary condition for $\left\|P_{a}\right\|<\infty$ for all real $a$. This is Theorem 1. Notice we need only consider $P_{a}$ for $0 \leqq a<1$, since if $a \geqq 1 P_{a}$ is not defined for all of $X$, since $X$ contains characteristic functions of intervals, and so in order that $\left\|P_{a}\right\|<\infty$ for any such $X$, we must have

$$
\int_{0}^{1} s^{-a} d s<\infty
$$

Another question we consider is the determination of conditions under which equality holds in (6), since a classical result of Hardy, Littlewood and Polya shows that when $X=L^{p}$ equality does hold ([3], p. 227). We show in Theorem 2 that if we consider the spectral radius of the operators involved, rather than the norm, then we do have

$$
r\left(P_{a}\right)=\int_{0}^{1} s^{-a} r\left(E_{s}\right) d s,
$$

where $r(T)$ denotes the spectral radius of an operator $T$. As a corollary of (8) we obtain conditions under which equality holds in (6) which includes the case $X=L^{p}$.

A final result, which may be useful when equality does not hold in (6), is given in Theorem 3. This improves the estimate in (7) and gives a similar estimate for the iterates of $P_{0}$.

Although the results will be stated only for the operators $P_{a}$, analogous results hold for $Q_{a}$. For, if $X^{\prime}$ is the associate of $X$, then it can be shown that the norm of $P_{a}$ as an operator in $X$ is equal to the norm of $Q_{a}$ as an operator in $X^{\prime}$. This is because $Q_{a}$ is the "transpose" of $P_{a}$. Combining this with the fact that if $h^{\prime}(s)$ is the norm of $E_{s}$ in $X^{\prime}$, then $h^{\prime}(s)=s^{-1} h\left(s^{-1}\right)$, we can obtain results for $Q_{a}$ by change of variable from those for $P_{a}$.

2. Preliminary lemmas. Recall that the spectral radius of an operator $T$ is the smallest number $r$ such that the disc $\{\lambda:|\lambda| \leqq r\}$ contains the spectrum of $T$. It is easily shown that if $\|T\|$ is the norm of $T$ as a mapping from a space to itself, and $r(T)$ is the spectral radius of $T$, then

$$
r(T) \leqq\|T\|
$$


It is important to notice that since we will be considering the same operator applied to many spaces that the spectrum, spectral radius and norm of the operator all depend on the space in which it acts. However, to avoid the constant repetition of hypotheses, it should be understood that whenever the norm or spectral radius of an operator appears, the operator is considered as a mapping from a given rearrangement invariant Banach space $X$ to itself. That is, all the norms appearing in any given theorem refer to the same space but the theorems apply to all rearrangement invariant spaces.

Lemma 1. Let $E_{s}$ be defined as in (3); let $X$ be a rearrangement invariant space; let $h(s)$ denote the norm of $E_{s}$, and $r\left(E_{s}\right)$ denote the spectral radius of $E_{s}$ as a mapping from $X$ into itself. Then

(i ) $h(s t) \leqq h(s) h(t)$

(ii) $h(s)$ is nonincreasing in $s$, and $\operatorname{sh}(s)$ is nondecreasing in $s$;

(iii) $\min \left(s^{-1}, 1\right) \leqq h(s) \leqq \max \left(s^{-1}, 1\right), \quad 0<s<\infty$.

(iv) Let $\theta(s)$ denote the ratio $[-\log h(s) / \log s]$ If $\alpha=\inf _{s<1} \theta(s)$ and $\beta=\sup _{s>1} \theta(s)$, then $\alpha=\lim _{s \rightarrow 0+} \theta(s)$ and $\beta=\lim _{s \rightarrow \infty} \theta(s)$, and $0 \leqq \beta \leqq \alpha \leqq 1$

(v) $r\left(E_{s}\right)=\max \left(s^{-\alpha}, s^{-\beta}\right)$. where $\alpha$ and $\beta$ are as in (iv).

Proof. Parts (i) to (iv) are proved in [1].

For part (v), we use Gelfand's formula for the spectral radius. Namely

$$
r(T)=\left.\lim _{n \rightarrow \infty}\left\|T^{n}\right\|\right|^{1 / n}
$$

where $T^{n}$ is the $n$th iterate of $T$. (See [4], p. 263.) Thus,

$$
\begin{aligned}
r\left(E_{s}\right) & =\left.\lim _{n \rightarrow \infty}\left\|E_{s}^{n}\right\|\right|^{1 / n} \\
& =\lim _{n \rightarrow \infty} h\left(s^{n}\right)^{1 / n} \\
& =\left\{\begin{array}{l}
s^{-\alpha}, \text { if } 0<s \leqq 1 \\
s^{-\beta}, \text { if } 1 \leqq s<\infty .
\end{array}\right.
\end{aligned}
$$

For by (iv), given $\varepsilon>0, \exists \delta(\varepsilon)>0$ such that for $0<s<\delta(\varepsilon) \leqq 1$ we have

$$
s^{-\alpha} \leqq h(s) \leqq s^{-\alpha-\varepsilon} .
$$

But, if $s<1, s^{n}<\delta(\varepsilon)$ for $n$ sufficiently large so that

$$
s^{-\alpha} \leqq h\left(s^{n}\right)^{1 / n} \leqq s^{-\alpha-\varepsilon}
$$

and this proves (9) for $0<s<1$. If $s>1$, a similar argument ap- 
plies. If $s=1, E_{s}$ is the identity so $h(1)=1$.

Lemma 2. Let $P_{a}$ be defined as in (1), and suppose $X$ is a rearrangement invariant space for which $\left\|P_{a}\right\|<\infty$. Then, for all $f \in X$, if $P_{a}^{n}$ denotes the $n$th iterate of $P_{a}$,

$$
P_{a}^{n} f(t)=\int_{0}^{1} s^{-a} \frac{1}{(n-1) !}\left(\log \frac{1}{s}\right)^{n-1} f(s t) d s .
$$

Also, if $\lambda$ is complex with $|\lambda|<r\left(P_{a}\right)^{-1}$, and $I$ is the identity operator, then $\left(I-\lambda P_{a}\right)^{-1}$ exists and is a bounded operator from $X$ into itself.

The following formula holds for real $\lambda$, with $|\lambda|<r\left(P_{a}\right)^{-1}$

$$
P_{a+\lambda}=P_{a}\left(I-\lambda P_{a}\right)^{-1} .
$$

Proof. Let $T$ denote the operator defined by the right member of (10), and suppose $\|T\|<\infty$. Then

$$
\begin{aligned}
P_{a} T f(t) & =\int_{0}^{1} u^{-a} d u \int_{0}^{1} v^{-a} \frac{1}{(n-1) !}\left(\log \frac{1}{v}\right)^{n-1} f(t u v) d v \\
& =\int_{0}^{1} d u \int_{0}^{u} s^{-a} \frac{1}{(n-1) !}\left(\log \frac{u}{s}\right)^{n-1} f(t s) \frac{d s}{u} \\
& =\int_{0}^{1} s^{-a} \frac{1}{(n-1) !} f(s t) d s \int_{0}^{1}\left(\log \frac{u}{s}\right)^{n-1} \frac{d u}{u} \\
& =\int_{0}^{1} s^{-a} \frac{1}{n !}\left(\log \frac{1}{s}\right)^{n} f(s t) d s, \quad \text { almost all } t \in R^{+},
\end{aligned}
$$

where the second line follows by the change of variable $s=u v$, and the interchange of order of integration follows from Fubini's theorem for almost all $t \in R^{+}$.

The fact that $T=P_{a}^{n}$ now follows easily by induction from (12) since it is true for $n=1$.

The statement that $I-\lambda P_{a}$ has a bounded inverse in $X$ for $|\lambda|<r\left(P_{a}\right)^{-1}$ is standard, and in fact

$$
\left(I-\lambda P_{a}\right)^{-1}=\sum_{n=0}^{\infty} \lambda^{n} P_{a}^{n},
$$

where the series converges in operator norm. (See [4], p. 262.)

Thus, if $f \in X$, 


$$
\begin{aligned}
& P_{a}\left(I-\lambda P_{a}\right)^{-1} f(t) \\
& \quad=\sum_{n=0}^{\infty} \lambda^{n}\left(P_{a}^{n+1}\right) f(t) \\
& \quad=\sum \lambda^{n} \int_{0}^{1} s^{-a} \frac{1}{n !}\left(\log \frac{1}{s}\right)^{n} f(s t) d s \\
& \quad=\int_{0}^{1} s^{-a} f(s t)\left\{\sum_{n=0}^{\infty} \frac{\lambda^{n}}{n !}\left(\log \frac{1}{s}\right)^{n}\right\} d s,
\end{aligned}
$$

for almost all $t \in \boldsymbol{R}^{+}$,

$$
=\int_{0}^{1} s^{-a-\lambda} f(s t) d s=P_{a+\lambda} f(t) .
$$

Here equation (10) has been used in the second line and the interchange of order of summation and integration follows by Fubini's theorem.

Lemma 3. Let $K$ be a measurable nonnegative function on $R^{+}$, and let $T$ be defined by the following expression for every $f$ for which the integral exists a.e.

$$
T f(t)=\int_{0}^{\infty} K(s) f(s t) d s .
$$

If $X$ is a rearrangement invariant space, and if $\|T\|<\infty$, considered as a mapping from $X$ to itself, then

$$
\max \left(h(s) \int_{0}^{s} K(t) d t, \operatorname{sh}(s) \int_{s}^{\infty} K(t) \frac{d t}{t}\right) \leqq\|T\| .
$$

Proof. The fact that

$$
h(s) \int_{0}^{s} K(t) d t \leqq\|T\|
$$

was proved in [1]. To establish the other inequality notice that if $T^{\prime}$ is the transpose of $T$ then

$$
T^{\prime} f(t)=\int_{0}^{\infty} K\left(\frac{1}{s}\right) f(s t) \frac{d s}{s} .
$$

And, if $h^{\prime}(s)$ is the norm of $E_{s}$ in $X^{\prime}$, then $h^{\prime}(s)=s^{-1} h\left(s^{-1}\right)$. Thus,

$$
h^{\prime}(s) \int_{0}^{s} K\left(\frac{1}{t}\right) \frac{d t}{t} \leqq\left\|T^{\prime}\right\|_{X^{\prime}} .
$$

But using the fact that $\left\|T^{\prime}\right\|_{X^{\prime}}=\|T\|_{X}$ and changing variables 
proves that

$$
\operatorname{sh}(s) \int_{s}^{\infty} K(t) \frac{d t}{t} \leqq\|T\|
$$

\section{Main results.}

Theorem 1. Suppose that $P_{a}, E_{s}$ are defined by (1). Then

$$
\left\|P_{a}\right\|<\infty \text { if and only if } \int_{0}^{1} s^{-a} h(s) d s<\infty .
$$

Proof. We need only consider $0 \leqq a<1$, and $\left\|P_{a}\right\|<\infty$. Let $\varepsilon>0$ satisfy $\varepsilon<r\left(P_{a}\right)^{-1}$ and $\varepsilon<1-a$. Then, from Lemma 2,

$$
P_{a+\varepsilon}=P_{a}\left(I-\varepsilon P_{a}\right)^{-1} \text { and }\left\|P_{a+\varepsilon}\right\|<\infty .
$$

Applying Lemma 3 to $T=P_{a+\varepsilon}$,

$$
h(s) \int_{0}^{s} t^{-a-\varepsilon} d t \leqq\left\|P_{a+\varepsilon}\right\|,
$$

and thus

$$
h(s) \leqq c s^{-1+a+\varepsilon},
$$

where $c=(1-a-\varepsilon)\left\|P_{a+\varepsilon}\right\|<\infty$.

Hence, we have

$$
\int_{0}^{1} h(s) s^{-a} d s \leqq c \int_{0}^{1} s^{\varepsilon-1} d s<\infty
$$

The converse follows from the inequality (6) stated earlier. To prove the next theorem we need a result which would be obvious if the entities involved were positive numbers rather than positive operators.

Lemma 4. Let $P_{a}$ be defined by (1), and let $\lambda>0$ be a positive number. Then,

$$
\left\|P_{a+2}\right\|<\infty \text { if and only if } \sum_{n=0}^{\infty} \lambda^{n}\left\|P_{a}^{n+1}\right\|<\infty .
$$

Proof. If $\left\|P_{a+\lambda}\right\|<\infty$, then $\left\|P_{a+\lambda+\varepsilon}\right\|<\infty$ for some $\varepsilon>0$ (and we may assume that $a+\lambda+\varepsilon<1$ as in Theorem 1). This follows from Lemma 2. Thus, from Lemma 3,

$$
h(s) \int_{0}^{s} s^{-a-\lambda-\varepsilon} d s \leqq\left\|P_{a+\lambda+\varepsilon}\right\|,
$$


so

$$
h(s) \leqq c s^{-1+a+\lambda+\varepsilon}, \quad \text { where } c<\infty .
$$

Thus, by the expression (10) for $P_{a}^{n}$, and the standard inequality contained in Theorem 3.1 of [1], i.e.

$$
\left\|\int_{0}^{\infty} K(s) E_{s} d s\right\| \leqq \int_{0}^{\infty} K(s)\left\|E_{s}\right\| d s,
$$

we have

$$
\begin{aligned}
\left\|P_{a}^{n}\right\| & \leqq \int_{0}^{1} h(s) s^{-a} \frac{1}{(n-1) !}\left(\log \frac{1}{s}\right)^{n-1} d s \\
& \leqq C \int_{0}^{1} s^{-1+\lambda+\varepsilon} \frac{1}{(n-1) !}\left(\log \frac{1}{s}\right)^{n-1} d s=\frac{C}{(\lambda+\varepsilon)^{n}}
\end{aligned}
$$

Thus

$$
\sum_{n=0}^{\infty} \lambda^{n}\left\|P_{a}^{n+1}\right\|<\infty,
$$

since it is majorized by a convergent geometric series.

Theorem 2. Let $P_{a}, E_{s}$ be defined as in (1), (3) and let $r\left(P_{a}\right)$, $r\left(E_{s}\right)$ denote the spectral radii of these operators as mappings from a rearrangement invariant space $X$ into itself, then

$$
r\left(P_{a}\right)=\int_{0}^{1} s^{-a} r\left(E_{s}\right) d s .
$$

Proof. By ([4], p. 262-Theorem 5.2-C),

$$
\begin{aligned}
{\left[r\left(P_{a}\right)\right]^{-1} } & =\sup \left\{\lambda \in C: \sum_{n=0}^{\infty}|\lambda|^{n}\left\|P_{a}^{n+1}\right\|<\infty\right\} \\
& =\sup \left\{\lambda>0: \sum_{n=0}^{\infty} \lambda^{n}\left\|P_{a}^{n+1}\right\|<\infty\right\} .
\end{aligned}
$$

But, by Lemma 4 ,

$$
\begin{aligned}
& \sup \left\{\lambda>0: \sum_{n=0}^{\infty} \lambda^{n}\left\|P_{a}^{n+1}\right\|<\infty\right\} \\
& \quad=\sup \left\{\lambda>0:\left\|P_{a+\lambda}\right\|<\infty\right\}=\lambda_{0}, \quad \text { say. }
\end{aligned}
$$

However, by Theorem 1, $\left\|P_{a+2}\right\|<\infty$, if and only if

$$
\int_{0}^{1} s^{-a-\lambda} h(s) d s<\infty \text {. }
$$

Thus since $r\left(E_{s}\right) \leqq h(s)$, and by Lemma $1, r\left(E_{s}\right)=s^{-\alpha}$ if $0 \leqq s \leqq 1$, we have 


$$
\frac{1}{1-\alpha-a-\lambda}=\int_{0}^{1} s^{-a-\lambda} r\left(E_{s}\right) d s<\infty,
$$

provided $\left\|P_{a+2}\right\|<\infty$.

Conversely, if

$$
\int_{0}^{1} s^{-a-\lambda-\alpha} d s<\infty
$$

then $a+\lambda+\alpha<1$, and so there is an $\varepsilon>0$ such that

$$
\int_{0}^{1} s^{-a-\lambda-\alpha-\varepsilon} d s<\infty \text {. }
$$

But this implies

$$
\int_{0}^{1} s^{-a-\lambda} h(s) d s<\infty
$$

by using part (iv) of Lemma 1.

Hence $\left\|P_{a+\lambda}\right\|<\infty$ if and only if $(1-\alpha-a-\lambda)^{-1}<\infty$. Hence,

$$
\lambda_{0}=\sup \left\{\lambda:(1-\alpha-a-\lambda)^{-1}<\infty\right\}=1-\alpha-a .
$$

Putting together (17), (18) and (20), we obtain finally that

$$
\begin{aligned}
r\left(P_{a}\right) & =\frac{1}{\lambda_{0}}=\frac{1}{1-\alpha-a}=\int_{0}^{1} s^{-a-\alpha} d s \\
& =\int_{0}^{1} s^{-a} r\left(E_{s}\right) d s .
\end{aligned}
$$

CoRollary. If $h(s)=s^{-\alpha}$ for $0 \leqq s \leqq 1$, then

$$
\left\|P_{a}\right\|=\int_{0}^{1} s^{-a} h(s) d s .
$$

Proof. By (6),

$$
\left\|P_{a}\right\| \leqq \int_{0}^{1} s^{-a} h(s) d s .
$$

But, by assumption $h(s)=s^{-\alpha}=r\left(E_{s}\right)$ for $0 \leqq s \leqq 1$. Thus, from the theorem,

$$
r\left(P_{a}\right)=\int_{0}^{1} s^{-a-\alpha} d s=\int_{0}^{1} s^{-a} h(s) d s
$$

and, since $r\left(P_{a}\right) \leqq\left\|P_{a}\right\|$, we have

$$
\int_{0}^{1} s^{-a} h(s) d s=r\left(P_{a}\right) \leqq\left\|P_{a}\right\| \leqq \int_{0}^{1} s^{-a} h(s) d s,
$$


which proves (22).

The final result involves the operator $P_{0}$ and its iterates. We shall now write $P \equiv P_{0}$.

Theorem 3. Let $K_{n}$ be defined by,

$$
P^{n} f(t)=\int_{0}^{1} K_{n}(s) f(s t) d s .
$$

we have

$$
\left\|P^{n}\right\| \leqq \int_{0}^{1} K_{n}(s) h(s) d s \leqq\left(2+\log \left(\begin{array}{c}
2 n \\
n
\end{array}\right)\right)\left\|P^{n}\right\|,
$$

where the norms of the operators involved are as mappings from a rearrangement invariant space $X$ into itself.

Proof. By Lemma 2,

$$
K_{n}(s)=\frac{1}{(n-1) !}\left(\log \frac{1}{s}\right)^{n-1} \chi_{[0,1]}(s) .
$$

Thus, we have

$$
\begin{aligned}
s \int_{s}^{\infty} K_{n}(t) \frac{d t}{t} & =s \int_{s}^{1} \frac{1}{(n-1) !}\left(\log \frac{1}{s}\right)^{n-1} \frac{d s}{s} \\
& =\frac{s}{n !}\left(\log \frac{1}{s}\right)^{n} .
\end{aligned}
$$

Thus, if $\left\|P^{n}\right\|<\infty$, then by Lemma 3 , we have

$$
s\left(\log \frac{1}{s}\right)^{n} h(s) \leqq\left\|P^{n}\right\| n !
$$

For convenience, denote $C_{n}=\left\|P^{n}\right\|$. So, if $C_{n}<\infty$, we have $C_{2 n} \leqq$ $C_{n}^{2}<\infty$.

Thus, applying (29) for $n$ and $2 n$, and part (iii) of Lemma 1 , we obtain

$$
h(s) \leqq \min \left(\frac{1}{s}, \frac{n ! C_{n}}{s\left(\log \frac{1}{s}\right)^{n}}, \frac{(2 n) ! C_{2 n}}{s\left(\log \frac{1}{s}\right)^{2 n}}\right) .
$$

Thus, if $t_{1}$, and $t_{2}$ are such that

$$
\left(\log \frac{1}{t_{1}}\right)^{n}=n ! C_{n}, \quad \text { and } \quad\left(\log \frac{1}{t_{2}}\right)^{n}=\frac{(2 n) ! C_{2 n}}{n ! C_{n}},
$$

then 
$(32)$

$$
\begin{aligned}
& \int_{0}^{1} K_{n}(s) h(s) d s \\
& \leqq \int_{0}^{t_{2}} \frac{1}{(n-1) l}\left(\log \frac{1}{s}\right)^{-n-1}(2 n) ! C_{2 n} \frac{d s}{s} \\
&+\int_{t_{2}}^{t_{1}} \frac{1}{(n-1) !}\left(\log \frac{1}{s}\right)^{-1} n ! C_{n} \frac{d s}{s} \\
&+\int_{t_{1}}^{1} \frac{1}{(n-1) !}\left(\log \frac{1}{s}\right)^{n-1} \frac{d s}{s} \\
&= C_{n}+C_{n} \log \left(\begin{array}{c}
2 n \\
n
\end{array}\right) \frac{C_{2 n}}{C_{n}^{2}}+C_{n} \\
& \leqq C_{n}\left(2+\log \left(\begin{array}{c}
2 n \\
n
\end{array}\right)\right)
\end{aligned}
$$

where we have integrated and used the definitions (31). This proves (26) since the left hand inequality is Theorem 3.1 of [1].

\section{REFERENCES}

1. D. W. Boyd, The Hilbert transform on rearrangement invariant spaces, Canad. J. Math. 19 (1967), 599-616.

2. - Space between a pair of reflexive Lebesgue spaces, Proc. Amer. Math. Soc. 18 (1967), 215-219.

3. G. H. Hardy, J. E. Littlewood and G. Polya, Inequalities, Cambridge, 1959.

4. A. E. Taylor, Functional Analysis, Wiley, 1958.

Received February 27, 1967.

UNIVERSity OF AlBerta,

Edmonton, Alberta, Canada

California Institute of Technology

Pasadena, California 


\section{PACIFIC JOURNAL OF MATHEMATICS}

\section{EDITORS}

\section{H. ROYDEN}

Stanford University

Stanford, California

\section{J. P. Jans}

University of Washington

Seattle, Washington 98105

\section{J. DUGUNDJI}

Department of Mathematics

Rice University

Houston, Texas 77001

RICHARD ARENS

University of California

Los Angeles, California 90024

\section{ASSOCIATE EDITORS}
E. F. BeCKenbaCH
B. H. NeumanN
F. WOLF
K. YosIDA

\section{SUPPORTING INSTITUTIONS}

UNIVERSITY OF BRITISH COLUMBIA CALIFORNIA INSTITUTE OF TECHNOLOGY UNIVERSITY OF CALIFORNIA MONTANA STATE UNIVERSITY UNIVERSITY OF NEVADA NEW MEXICO STATE UNIVERSITY OREGON STATE UNIVERSITY UNIVERSITY OF OREGON OSAKA UNIVERSITY UNIVERSITY OF SOUTHERN CALIFORNIA
STANFORD UNIVERSITY UNIVERSITY OF TOKYO UNIVERSITY OF UTAH WASHINGTON STATE UNIVERSITY UNIVERSITY OF WASHINGTON

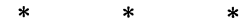

AMERICAN MATHEMATICAL SOCIETY CHEVRON RESEARCH CORPORATION TRW SYSTEMS

NAVAL ORDNANCE TEST STATION 


\section{Pacific Journal of Mathematics}

\section{Vol. 24, No. $1 \quad$ May, 1968}

Harry P. Allen, Lie algebras of type $D_{4}$ over algebraic number fields ...... 1

Charles Ballantine, Products of positive definite matrices. II............ 7

David W. Boyd, The spectral radius of averaging operators ............ 19

William Howard Caldwell, Hypercyclic rings ................... 29

Francis William Carroll, Some properties of sequences, with an application

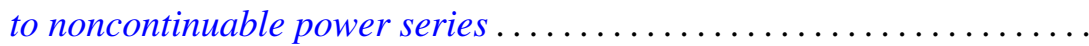

David Fleming Dawson, Matrix summability over certain classes of

sequences ordered with respect to rate of convergence ........... 51

D. W. Dubois, Second note on David Harrison's theory of preprimes. . . . . 57

Edgar Earle Enochs, A note on quasi-Frobenius rings.............. 69

Ronald J. Ensey, Isomorphism invariants for Abelian groups modulo bounded groups ................................ 71

Ronald Owen Fulp, Generalized semigroup kernels ................ 93

Bernard Robert Kripke and Richard Bruce Holmes, Interposition and approximation ................................. 103

Jack W. Macki and James Sai-Wing Wong, Oscillation of solutions to second-order nonlinear differential equations ..................

Lothrop Mittenthal, Operator valued analytic functions and generalizations

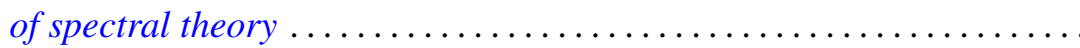

T. S. Motzkin and J. L. Walsh, A persistent local maximum of the pth power deviation on an interval, $p<1 \ldots \ldots \ldots \ldots \ldots \ldots \ldots \ldots \ldots \ldots . \ldots \ldots$

Jerome L. Paul, Sequences of homeomorphisms which converge to homeomorphisms ...........................

Maxwell Alexander Rosenlicht, Liouville's theorem on functions with elementary integrals.

Joseph Goeffrey Rosenstein, Initial segments of degrees .

$\mathrm{H}$. Subramanian, Ideal neighbourhoods in a ring ............

Dalton Tarwater, Galois cohomology of abelian groups . .

James Patrick Williams, Schwarz norms for operators ... .

Raymond Y. T. Wong, A wild Cantor set in the Hilbert cube. 